Rieko Sawyer

\title{
Identity Formation through Brokering in Scientific Practice
}

\begin{abstract}
Inspired by recent theorization by Dreier and Lave concerning situated perspectives on learning, I illuminate learning of international graduate students in a science lab in Japan as trajectories of participation in multi-layered activities and various mutually constituted occasions, and as crossing of multiple communities of practice. By doing so, I describe trajectories of participation as unique and multiple ways characteristic of individual participants instead of as a linear process from newcomer to old-timer or from peripheral to full participation in a community of practice. Identity formation is also reformulated as discovering and constituting one's unique self through crossing multiple communities of practice rather than merely as becoming a member in a community of practice. Further, I show that identity formation may be regarded not merely as adjusting the relationship among multiple communities within individuals, but as the practice of organizing new linkages among communities and of reconstituting communities of practice.
\end{abstract}

\section{Introduction}

In this paper, I shall describe learning as a trajectory of participation and as a mode of participation in communities of practice (Lave \& Wenger, 1991; Wenger, 1990, 1998) by focusing on international graduate students (henceforth, IGSs) in a science lab in Japan.
Lave \& Wenger (1991) and Wenger (1990, 1998) described the mode of participation and the identity formation in a community of practice as a seemingly linear process from a peripheral to a full participation, or from a full to a marginal participation. A stereotypical view of the apprenticeship process (a newcomer becoming an old-timer, an apprentice becoming a master) seems to be the backdrop of this view of the trajectory of participation. However, whether in a workshop in a traditional society (Ueno, 1999) or in a science lab at a university, once we enter a field, we realize that there are varieties of activities, occasions (formal as well as informal ones), and various members with different backgrounds participating in a community of practice. In short, participation in a community of practice cannot be delineated as a linear process. Rather, it is more multiple in nature.

First, I shall show how and to what extent IGSs were able to access machines. In the scientific practices of a lab, access to machines represents participation. Through examples, I shall show how lab members' access to machines is socially organized, and how members' participation in various activities and occasions facilitates or restricts access to machines. 
Second, through the lens of Goffman's (1959) notions of front stage/backstage I shall take a closer look at the various activities and occasions available to lab members as well as at how they are organized. I shall also argue how the organization of activities and occasions reflects power relations in the community of practice.

Third, drawing on examples of IGSs and their Japanese peers, I shall illustrate that participation is a way of finding or constituting one's unique position in a community of practice rather than merely a linear process from the periphery to full membership.

Finding or constituting one's unique position is directly related to the formation of a new and unique identity in a community of practice. In other words, the formation of identity may be accomplished by discovering and constituting unique aspects of one's self through participation in a community of practice. Furthermore, discovering and constituting unique aspects of oneself is accompanied by participants' involvements in multiple and concurrent communities.

\section{Participation in a scientific community of practice}

To begin with, let me briefly introduce the background of this study. The research site was an applied physics lab at a large Japanese university. The materials in this paper stem from my fourth year in this field. The main participants in my study were Japanese government sponsored European students. There were about 17 Japanese students, 4 IGSs and 4 faculty members in this lab. The lab held two offices. In the main office, the majority of students and the IGSs had their desks lined up next to each other. Graduate students came to the lab every day and spent extensive hours there. Most of the time they appeared busy with research related activities.

In an experimental science lab, access to machines and equipment is very important for lab members since these tools are instrumental to their research. Some machines and equipment are very delicate and must be handled with care. Furthermore, the operation of these machines is complicated, and descriptions in manuals alone do not outline the lab specific applications of specific instruments. Additional manuals created by lab members are evidence of this.

The knowledge of how to operate delicate and complicated machines is socially distributed, and members in the lab help each other and learn from one another when using the machines. One member alone is unable to describe all the details of how to operate these machines.

In this section, I shall describe learning as a trajectory of participation and as a mode of participation in a community of practice, focusing on IGSs in a science lab in Japan. I shall show how and to what extent IGSs were able to access machines, focusing on two European master level IGSs: Karl and Max. By doing so, I shall attempt to show how lab members' access to machines is organized, and how members' trajectories of participation made their access to machines possible or impossible. Access to machines is typical of the mode of participation in scientific practices in the lab.

\section{Social organization of access to machines in the lab: Karl's case}

For a while, Karl worked strange hours, such as from 4:00 to 8:00 in the morning, because his experiments required other machine settings than the experiments his Japanese peers were conducting. I said to him that it was very considerate of him to conduct his research at such odd hours, but he replied, "I call it survival." The Japanese students regarded his schedule as odd. One Japanese student said that Karl's behavior was anti-social. In fact, avoiding the need for communication was part of Karl's motivation for working at such odd hours. 
Some Japanese students were unhappy with Karl's use of the machine. The main user of the machine, Toshi, made a schedule for the use of this machine, and that made Karl's access to the machine almost impossible. Karl was upset by this. Eventually, although he had to spend several hours commuting every day, he decided to conduct his experiments at another institute where he did not have to share a machine with anyone.

I knew Toshi was not very fond of English speakers, including me. Thus, when I heard about this incidence from Karl, I thought Toshi was trying to be mean and prevent Karl from using the machine. In fact, Toshi was trying to keep Karl away from his machine, and because Karl's access to this machine was restricted, he could not participate in the practices of the lab.

\section{Toshi's account}

However, later interviews with Toshi revealed a different reasoning. He told me about the importance of "trust." For him, the machine was his treasure. He did not want someone he could not trust using his machine.

Toshi said that Japanese science students knew where other Japanese students were. If one student's experiment ended early, then he could adjust the schedule easily by contacting his peers. Furthermore, they could talk about any problems they experienced in using the machines. On the other hand, Toshi said that he had no idea where the IGSs were. In Karl's case, Toshi did not even know why this person was in the lab, what kind of research he was conducting, or how long he was staying in the lab.

To explain why he could not trust Karl, Toshi said that one day Karl adjusted the angle of the mirror in the machine. While Toshi was upset, Karl believed this change in angle would improve his and the lab's research. Karl told me that if one could not reproduce the same results under the same condition, it is not science. For him, changing the angle was not just for his purpose, but also for the lab, and for a better science, but Toshi did not share that belief.

Karl's case illustrates how machines are socially organized in labs. In experimental science labs, lab members work with complex and delicate machines. The lab members usually work in groups, and since all members share the machines in the lab, they must effectively negotiate their schedules. For some experiments, the experimenter needs to change the settings of a machine or the type of gas (Nitrogen or Oxygen, for example) and other substances used. Japanese students did not want other users to change the machine settings because someone's data might be ruined in the process. According to Toshi, it is very important for members to share machines only with those they can "trust."

\section{Organization of Participation: Max's Case}

Another IGS in the lab, Max, was successful in accessing the machines. Max knew where all the machines were although there were machines in many different places on campus and even in different institutions off campus. How was that possible? An informal network of first year Master of Science (MS) students helped Max gain access to the machines. This network was formed in the course of participating in activities organized by the lab (such as the summer trip, fall hiking, and eating lunch and dinner together). In this network, Max could ask his peers where the machines were or how to use the machines. He also became someone whom others could "trust." They constructed mutually trustworthy relationships. His access to machines became possible by participating in formal as well as informal activities.

\section{Comparison of the two cases}

The activities of master students in the lab are composed of academic and non-academic activities. The activities may also be divided into "formal activities" organized by the 
university and the lab (institution-initiated), and "informal activities" led by the students themselves. Thus, the activities are classified into four categories. Of these four categories, Karl participated only in academic activities, namely "informal academic" and "formal academic activities." Max, on the other hand, participated in all four categories of activities. As a student in the master program, Max had become involved in various activities with his Japanese peers. For example, it was necessary for Max to ask his student peers in the first year master program (called M1) about course homework because he had to attend classes as a formal academic activity. These opportunities for asking about homework are "informal academic activities." Furthermore, because of his position as a new master student in the lab, Max was naturally allocated the role of one of the organizers of lab events such as the picnic and summer trip.

In this way, Max had many opportunities to interact with his Japanese peers and, as a result, became trusted by other lab members. That is how he could know the location of various machines and equipment as well as what kind of research could be conducted in the lab. Max could get to know the details of how to deal with machines and equipment far beyond the information provided in the machine manuals. These are vital resources for students to conduct experiments, or to practice science. These informal and formal activities are complementary.

On the other hand, Karl was an exchange student, and not an official student at this Japanese university. As such, he did not have to attend classes (formal academic activity), nor did he have to participate in preparation for lab events (informal non-academic activity), which lab members perceived as an extra chore. Consequently, Karl and the Japanese students did not have any chances to get to know each other, and Karl failed to win the trust that was necessary for access to the machine. Although they started in similar positions in the community of practice, in the end Karl and Max's modes of participation and their trajectories became quite different.

In this section, I showed two things. First, by analyzing how two IGSs were able to access machines to different degrees, I illustrated that access to lab practices is socially organized. I demonstrated how the access to machines in labs is socially organized. This facet of access became visible by focusing on contrasting cases of two IGSs. Secondly, I showed how their trajectories of participation were different and how these differences facilitated or restricted their access to scientific resources.

This situation illustrated how formal and informal activities, or canonical and non-canonical practices (Brown \& Duguid, 1991), are inseparable, deeply related to each other and cannot be organized by themselves. The constitution of an informal activity and a noncanonical practices depends on the ways in which the formal activity or canonical practices are organized.

Related to these issues, Wenger (1990) presents the following analysis of the reason why newcomers to the insurance company Alinsu felt a major difficulty: Although they form a network among newcomers in their training class, they were placed in different divisions. Hence, they were unable to maintain this network on the floor. Moreover, on the floor other claims processors were constantly feeling pressured, and they did not recognize the need to help newcomers. Thus, newcomers were isolated, and many left the job in a matter of a few weeks. This case shows that the training class was there for training but also created opportunities for newcomers to form an informal network. The case of Max is the opposite of those claims processors. In the science lab, the informal network formed in classes was continuously maintained and helped Max gain access to machines and other resources on the floor (i.e., the experimental rooms). 
Regarding informal occasions, Wenger (1990) argues that for claims processors in an insurance company the daily work and participation in informal rituals (such as the celebration of someone's birthday or the exchange of Christmas presents) are complementary and constitute the texture of the practice as a whole. Not only is participation in informal activities complementary to formal activities, participation in informal activities also supports the formal activities (i.e., facilitates access to machines to conduct research).

In short, the case above illustrates that participation in a community of practice, such as conducting experiments in a graduate science lab, is not merely participation in a single activity. Participation is accomplished by interacting with community members in various interwoven activities that, on the surface, may appear to be more or less related to the central activity.

\section{Organizing front stage and backstage}

In the previous section, I showed that access to machines was enabled by participation in a variety of formal and informal, academic and non-academic activities which were mutually interwoven. However, formal and informal, academic and non-academic activities are merely the institutionalized joint enterprises of the community of practice. In reality, diverse occasions are organized within these institutionalized activities. In the following, we shall examine events organized in the community of practice of the lab in more detail.

In the lab I noticed that graduate students behaved differently depending on the presence of faculty members. These situations were marked differently according to time, space, and the words or registers used. This takes us back to Goffman's (1959) discussion of front stage and backstage.
Goffman cites de Beauvoir's (1953) description of women when men are absent (pp. 112-113). When men are around, it is a front stage for women and when they are not around, it is the women's backstage. On the backstage, performers are able to relax and prepare for their front stage performance. Likewise, in the case of Goffman's Shetland Hotel (1959), the workers behaved very differently in the kitchen, which is their backstage, and in front of the guests in the dining room, which is their front stage. The guests are the audience, and the workers are the performers. In the lab, the faculty members are the audience, and the students are the performers. The following examples illustrate this point.

\section{Case 1: When faculty members are not around}

The organization of the social space in the lab changes when no faculty members are around. In this university, associate professors, research associates, and technicians share offices (which I call labs) with students. When the faculty members had gone home, the students turned on the TV and started watching baseball games or movies. Student interaction was livelier when no faculty members were there. At those times, the students could relax and find spaces to share their research interests. Students often said that they did not know what the others were studying. Of course, they had some idea, but because of the specific nature of their respective research and the formal nature of interaction during the day, they could not fully understand the research of other members. However, the backstage talk that occurred after hours was a vital source of information concerning their research as well as of who they were. One student said, "It is important to ask what someone is doing when you have free time in the middle of the night (while waiting in an experiment). This seemingly useless interaction is very important." 


\section{Case 2: Honda-san's room}

Case 1 was an example of the backstage being organized after a certain time of day (or in the weekends). The following is a case of how spaces construct the backstage. It is similar to Goffman's (1959) description of the Shetland Hotel where certain spaces are constructed as a backstage.

One faculty member, Honda, was a technician. Although he did not have to teach any classes, he was called Honda "sensei" (a respected title for teachers), or Honda "san" (means Mr.), and he was respected for his extensive knowledge of machines, his skills and other abilities. His room was called "Mr. Honda's room," and that was where many students took a break. He joined the students when they were noisy and having fun. Students told me they go to the room together after their joint meals as well as before and after classes. They would then discuss issues such as how to solve homework problems and talk about other things than science.

"Mr. Honda's room" was also called the "tobacco room" because smoking was allowed there. Honda was a smoker, and he liked to talk to students and teach students not just physics, but different kinds of things. Students who smoked often went to this room to relax and talk to other students. Some students did not go to this room because it was noisy. Max started coming to this room when he started smoking in the fall of the second year of the master program. Eventually, he moved to this room.

There was also a TV and sports newspaper in this room. Japanese students watched sports (e.g., baseball or soccer) or movies on TV when the faculty had gone home or on weekends. Max watched TV with his Japanese peers, but I heard that other IGSs did not watch TV. One day, I saw him asking about a character in a popular Japanese drama.

\section{Time and space, front stage and backstage}

Honda's room was a backstage where students relaxed in between their front stage of classes, presentations at lab meetings or conferences. They prepared for their front stage performance by doing homework or making PowerPoint slides in Mr. Honda's room. It was a space for backstage activities. The backstage was also organized temporally. The students' relaxed behavior could be observed when the faculty had left.

Even though Honda held a faculty position, he was connecting the front stage and backstage. The fact that he was not in the position of evaluating students formally put him in this position.

\section{Case 3: Mimicking and ridiculing faculty during a summer trip}

Front stage and backstage behavior was also observed in other places than Honda's room. I had a chance to go on a summer trip of another lab. Summer or winter trips are a common activity in science labs. Cases of both front stage and backstage behavior could be seen on this trip. For example, the dinner party on the first night with faculty members was mainly a formal, on-stage situation. The seats were arranged such that faculty members sat in the front of the room, called the kamiza area (literally meaning upper seats reserved for persons with a higher status). Students sat with members conducting similar research or with others of the same status (first year master students, for example.) The dinner started with the professor's speech. After dinner, students got together in one of the students' room and continued drinking alcohol without faculty members. Students would report interactions with faculty members and tell others how silly they thought the faculty members were, and other members would laugh about it together, and drink some more. They also shared descrip- 
tions of how they were treated or what they were told by faculty members and took turns mimicking them. Similar examples are reported in Goffman (1959) in service encounters and in the kitchen area of the Shetland Hotel. Workers mock customers and behave differently when customers are not around. According to Goffman, the characteristics of backstage are, "reciprocal first-naming, co-operative decision-making, profanity, open sexual remarks, elaborate griping, smoking, rough informal dress, 'sloppy' sitting and standing posture, use of dialect or sub-standard speech, mumbling and shouting, playful aggressiveness and 'kidding', inconsiderateness for the other in minor but potentially symbolic acts, minor physical self-involvements such as humming, whistling, chewing, nibbling, belching, and, flatulence." (p. 128) Most of the description fits the behavior seen in private spaces shared by students during the lab summer trip.

Goffman points out that bad mouthing in the backstage has the function of maintaining solidarity between members. In the case of a lab, bad mouthing of faculty members, or of people in powerful positions, may be interpreted as a reconfirmation of their memberships and the social display of camaraderie. In other words, by constituting a backstage, students are creating a sub-community with a relatively different position from the faculty in the science lab.

This front stage/backstage behavior and organization of space cannot be separated from the power relations of the community of practice. Whether in a hotel or a lab, the social relationship in the front stage is not symmetrical. Workers obey customers and provide service, and students obey faculty members, work for them and refer to a professor as a "boss," or even "God." The backstage behavior of hotel workers or students is performed in response to the social relationships in the front stage. Moreover, the front stage/backstage contrast was organized within asymmetrical relations of social power.
We may say that participation as a graduate student in a lab community of practice is constructed by participation in the dual context of front stage and backstage. Becoming a member in a lab community of practice includes participation in the backstage as well. In other words, participation means participating in a social organization where power relations are constructed, rather than participating in a flat organizational structure. While a linear model of apprenticeship in a community of practice devotes little discussion to power relations, the description and discussion of front stage/ backstage behavior help illuminate the power relations in a concrete manner.

Østerlund (1996) reports related cases. According to Østerlund, salespeople often move between business talk and informal conversation. For example, a salesperson called Carol would manage to interweave small conversations about her customer's children and golf. Her constant moves between different themes and issues, informal as well as formal, would help her get a feel for the customer and learn what area they may share. Østerlund's case may be regarded as an instance of organizing a backstage in the interaction between a salesperson and customer. Salespeople seem to endeavor to organize a backstage in order to establish a different social relation beyond the relation of salesperson and customer.

Use of dialect serves a similar function. It marks attempts to organize a backstage and establish a specific social relation among participants in interaction.

\section{Language choice and the organization of boundaries}

Whether a certain situation is front stage or backstage, or at the boundary between them, is not only marked by time and space but also by the use of certain words or the choice of register/ language. Let me show some cases concerning language choice and organization at the boundary between front stage and backstage. 
In this lab, the use of a dialect was an example of language choice. Students prepared presentation materials the day before, or even until a minute before, it became their turn in periodic lab meetings. In the lab meetings, the professor would use both standard Japanese and a dialect whereas the Japanese students used formal Japanese. This indicated that while this meeting was the front stage for the students, it was a backstage for the professor in his preparation for the front stage of conferences, or for the final public presentation of master's and doctoral students. In the boundary space of the periodic lab meetings, the two kinds of stages are multilayered.

\section{The Use of English}

The use of English by IGSs was a marked behavior in boundary contexts. On the other hand, the use of English for Japanese students is a performance on the front stage. To them, the occasional presentations in English by selected members of the lab as well as all kinds of situations where they needed to use English to interact with IGSs seemed like the front stage. The Japanese students had to use English with IGSs to explain how to use a machine, when to use tweezers, when to use disposable gloves to maintain a clean environment, how the maintenance of a machine was progressing, whom to talk to when a certain chemical ran out, how much money they need to collect (to buy presents to express farewell feelings of gratitude), when to pay for participating in a certain lab activity, etc. In these situations they needed to display their English ability, which they acquired in school in order to pass exams. Their backstage language was casual Japanese (a mixture of standard and dialect spoken in the area) and certainly not English.

The use of English was bound to organize a particular situation. It was recognized as a special situation because, when a Japanese student used English with an IGS, teasing of this Japanese student by peers was observed. In that way, Japanese students created a bound- ary by showing resistance toward the use of English. For many Japanese students in this and other labs, communicating in English was painful. They learned English as a subject to pass exams, not for communication in real life. English could be a source of embarrassment, not an enjoyable tool of communication to open doors for wider possibilities of knowing other people or other cultures. One student explained his difficulty in communicating with IGSs to me, "I have to communicate in my lower than junior high school level English." Another Japanese student Jun's case also shows how the use of English is a particular situation. Other Japanese students laughed at Jun when he presented in English at the first meeting after his return from studying in a European lab. Jun's case will be explained in detail later.

Another reason why situations of speaking English appeared to be on the front stage is that the professor had no problems with speaking English. He was an active scholar, and he had spent some time in the U.S. doing research. Thus, for him speaking English was different but nothing special. The European IGSs in this lab presented in English at the lab meetings, and they consulted with him in English when they needed to talk to him in person. When Japanese students talked to him, it was formal Japanese, and the content of the talk was usually about business such as research related matters (about the progress of the ongoing research, for example) or matters of lab organization (the availability of the professor for detailed scheduling of organized lab activities, for example). Both the use of formal language and the content of conversations between the Japanese students and their professor indicate that he certainly belonged to the front stage, and his facility with English marked the language as a front stage means of communication.

The following case shows how language choice marked the front and backstage of the community. Toshi said that he did not want to 
study English in order to communicate with IGSs. He would learn it when it became necessary. Some Japanese members also perceived the use of Japanese as an indication of IGS willingness to participate. On the other hand, another student, Fumiko who came from a lab at another university, did not feel special about the use of English because it was part of the practices in her previous lab. There everyone used English, including broken English and mixtures of Japanese and English words. The use of English constructed a front stage where Japanese students could not behave freely. On the other hand, speaking only casual Japanese, resisting IGSs and bad mouthing indicate backstageness. Speaking English, even if the sentence structures are not correct or the two languages are mixed, indicates that the boundary is not organized by language. These cases illustrate that speaking English had the function of organizing a special boundary in the science lab.

I observed that students began to feel less resistance toward using English a few years after European IGSs first came to the lab, and after having Japanese members such as Jun or Fumiko share their practice of using English learned in other contexts. From the examples above, we may say that it is vital for a community of practice to learn and change in order for IGSs to participate.

The cases above illustrate various front stage and backstage situations organized in the lab community of practice in addition to the formal and informal activities previously discussed. The fact that various situations are organized shows that various boundaries are constructed and enable different courses of member access.

These cases make us understand that participation in a community of practice is a very tricky business. To participate in a community of practice does not mean participating in flat, monotonous and sequential activities. Rather, participation is accomplished by taking part in various interwoven activ- ities or situations, or by constructing activities, situations, and boundaries.

If the activities and situations organized in a community of practice and the modes of participation in a community of practice vary, the formation of identity in a community of practice must also vary and reach beyond merely becoming a member. Moreover, identity formation seems related to trajectories of participation in intersecting communities of practice and not just to a single trajectory of participation within a unique community of practice. In the next section, we shall look at cases in which multiple modes of participation and multiple modes of identity formation are related.

\section{Participation through finding and constituting a unique self}

As shown in Fig.1, previous research (Lave \& Wenger, 1991; Wenger, 1998) describes participation in a community of practice and identity formation as a linear process from peripheral to full participation or from full to marginal participation. However, as already illustrated, in a community of practice there are a variety of activities and occasions including

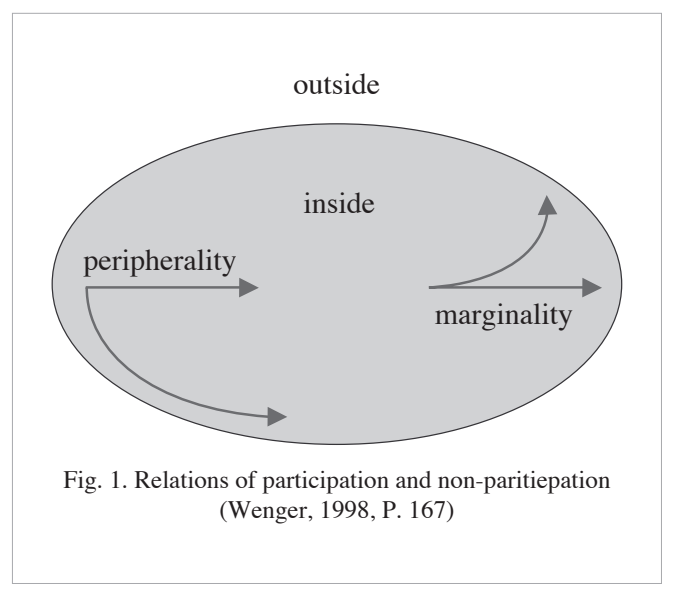


formal/informal ones and front stage/backstage performances. Furthermore, in a community of practice there are various members with different backgrounds, and their modes of participation are not unitary but diverse.

If the mode of participation is diverse, "finding or constructing one's position" in a community of practice may also encompass three issues as shown in the following:

First of all, by finding a position in a community of practice, it is possible to discover and form a different self. In short, the actual structure of participation may be redefined as finding a new position involving the creation of a new identity, which goes beyond merely becoming a member of a community of practice. In this way, the formation of identity in a community of practice may be conceptualized as discovering and constituting unique aspects of one's self.

Second, seeing participation as finding a new position in a community of practice is the flip side of creating one's new identity.

Third, identity formation as discovering and constituting unique aspects of oneself by participating in a community of practice is closely related to one's crossing of multiple communities as Dreier (1999) and Lave (1997) argue. A unique position or unique aspects of oneself are made visible and come into being through one's trajectory of participation across multiple communities of practice as in the case of "knowledge brokers." Wenger writes about this notion in Wenger (1990, p. 164) and in so doing refers to the work of Eckert (1989) as pursuing similar lines of thought. A knowledge broker has a unique position in a community of practice by participating in other communities as well. S/he may introduce new styles and new ideas into their/her/his peer groups. Styles and ideas then come into being as a result of a broker crossing communities. By introducing new styles and ideas from other communities a broker may find and constitute a unique position and self in a community of practice.
Finding a position leads to organizing learning opportunities as well. Depending on one's position in the community of practice, one's learning opportunities may become confined, as in the case of Karl. On the other hand, depending on one's position, one's learning opportunities may also become facilitated, as in the case of Max.

In the examples below I want, first of all, to illustrate the identity formation of brokers who move across communities of practice and bring new knowledge and trends into a community of practice.

\section{The case of Max's English}

As mentioned before, Max was trying to become a member of a Japanese MS student community of practice, and he succeeded. Through this process of becoming a member, his uniqueness became increasingly clear too. For example, he became an authority of English. Upon his arrival in Japan, Max's English was not very fluent. I had a hard time understanding his English when talking with him. He generated certain systematic grammatical errors by trying to transfer his first language speech into English. He also tried certain expressions used in his first language in English, which did not work. For example, the English word "probe" means something different in his first language. He also told a Japanese peer that "private" means bathroom. During his years in Japan, his English has become quite fluent. Once I heard Nagata, a Japanese master student, ask him "how a native speaker felt," although Max was not a native speaker of English. Having a Caucasian appearance, and being advantaged in his linguistic background (for example, his first language and English share the use of the same alphabet, as opposed to Chinese characters used in Japanese), he became an authority of English in the lab community of practice. For instance, when Tamada, another master student, was told to prepare an English version of his paper, Max helped him with his English writing. 
Max said, "My English became much better. In my country, I could speak English. No problem. But I had problems communicating. Here (in Japan) reading is OK and listening." I asked him how he improved his English. He said, "By talking to others. Talking, talking, talking, and talking to my friends." I said, "So the fact that Karl was here was good." Max responded, "I talk five times more to my neighbor and his wife (a foreign couple, one of them lived in the US before). The problem is that they don't drink beer like Karl. I talked to my friends in English before. I didn't do that when I was in the Japanese Language Intensive course." One day when we were talking, I was surprised that he was talking like a member of the Italian Mafia in New York. When I told him that, he laughed and I noticed that he was downloading a mafia movie with Al Pacino and Robert De Niro. It was interesting and even somewhat entertaining to see a European graduate student speak like a member of a New York Italian Mafia in his science lab in Japan surrounded by Japanese students. He also read English newspapers on the internet. His connection with other foreigners and English, especially American English, resources was evident, and that helped him improve his English.

Although Max's case may seem exceptional, I have observed other European students improve their English as well. On the other hand, Japanese students would not improve their English even if they spent a long time in a lab. Why?

When government sponsored international students arrive in Japan, they move into dormitories prepared for international students. There, students form informal network. A few years later, they must move out from the dorms, but they keep the network. Once I went to the farewell party of an international student. He was another Eastern European who improved his English. At his farewell party, I was surprised to meet so many people in his small apartment. They were from different countries and different parts of the world: Eastern and Western Europe, the U.S. and South America. There were Asians who spoke English well, and some of them had been living in Japan, while others had just arrived. They studied different fields such as medicine, Japanese literature, engineering though he himself was an economics major. There were people from other universities and institutions too. He even received a phone call from a Brazilian who was back home on vacation calling to say goodbye to him during his party. I also heard international students saying that they went to a birthday or farewell party of somebody they had never met before. In this kind of private foreigner party, you are invited if you are a friend of a friend, and the foreigners use English to exchange all kinds of information and make comments about the Japanese. This is how they improve their English while living in Japan. Japanese students will not improve their English because they do not have connections with the English speaking community even though they have spent a long time in a lab.

IGSs know more about the conditions in other labs while Japanese students often say that they do not know what it is like in other labs. IGSs use information about the conditions in other labs to negotiate certain things with faculty members in their labs. This is further evidence of the existence of a foreigner community and network.

IGSs are keen on gathering more information through informal networks to make up for their limited communicative and linguistic ability in Japanese.

Returning to Max's case, he acquired English skills by being part of an English speaking community, and he brokered these skills into the lab. This was a part of his identity as a broker. Being a member in another community, a community of English speakers, was a very important resource for Max to cross boundaries and to broker. By being a member 
of this community, he improved his English while staying in Japan. By being recognized by Japanese members he could broker his English skills. This became possible because he participated in various lab activities. Through his participation, other members in the community of practice had more opportunities to recognize his skills. However, Karl who was fluent in English from the beginning, did not have a chance to be recognized as such because he did not participate in the lab activities as Max did.

This shows two things. First, English had the potential of becoming his linguistic capital (Bourdieu, 1977) with the approval of the members of the community of practice. Max built his identity of "Max, the English expert" by utilizing this linguistic capital as a core of his identity in the community of practice. Second, the fact that Max's English improved while he was in Japan, implies his participation in the English speaking community.

\section{The case of Max's math}

Max was also accepted as the person who was good at math. On the day of the final examination, as soon as the professor left, Japanese first year master students gathered around Max and copied his answers. Later he told me this story several times with a smile. How did Max gain so much trust among the Japanese members that they would copy his answers?

Max was very good at math and physics. He said, "I didn't have to study hard. I don't know why but I always got good marks in math and physics." Because the level of math education in his country was higher than in Japan and because he was talented in math, math was not a problem for him.

However, in the beginning he experienced difficulties in classes. For example, in one small exam, he could not understand the exam question because it was written in Japanese. On top of that, the professor left the room hastily, and Max did not have a close enough Japanese friend whom he could ask to translate the question into English during the limited time of the examination. Around that time, when Max was trying to find out about homework, I observed a Japanese member treating him in an unfriendly manner. While being treated like an outsider, Max told me "First year master students are the most important people (in his lab life)." At that time, Max was trying to enter the first year master student community of practice, but did not quite know how to do that and was roaming around it. His math ability was not recognized as a capital when he was in his own country. However, in Japan, thanks to his math ability, and despite the fact that he was weak in Japanese, he had an advantage over other students. One student told me that Max's math ability impressed him when he was copying Max's homework. Japanese students discovered his math ability and eventually accepted him as a person with math ability. He was accepted by participating in the various formal and informal lab activities with first year master students. They trusted Max's math ability, and they trusted him not to tell any faculty member about their conduct. Max became a trusted member in this community of practice, and that was how Japanese students felt comfortable enough to copy Max's answers. By brokering his math ability, he found a new position in the lab.

Case 1 and 2 show the formation of Max's identity as a broker. Cases like Max's were also observed among Japanese members. In the following section, I shall introduce the cases of two Japanese students: Fumiko and Jun.

\section{The case of Fumiko}

A doctoral student, Fumiko was different from most of the other students. Besides being the only female student, she had a working experience in a company, and she had also studied at another university. Since the majority of the students come from the undergraduate program of the same university, by the time they come to labs as senior or master students they usu- 
ally know or at least recognize each other from classes they took. In this sense, she shared more similarities with IGSs than other Japanese students did. She knew no one, and, like Max and Karl who were non-Asians, she stood out because of her appearance as a female. Like Karl, she did not have to take classes with other members of the lab. Moreover, her status as a doctoral student automatically exempted her from all preparation chores related to lab activities. As mentioned earlier, these preparation chores had no academic value but helped a newcomer build a network which led to access to various kinds of resources in the lab.

Because of her restricted participation and status as a newcomer, she was at first in a disadvantaged position. However, she was successful in finding her position in the lab community of practice. In this lab, students did not know how to use a lathe machine, or a milling machine (she called this "metalwork"), but Fumiko knew how to use it since she came from another lab. One day I noticed her shaving her fingertips with a knife. I was surprised and asked her what she was doing. She told me that it was not painful and that when one has used a lathe machine, one has to remove small pieces of metal from one's fingers with a pair of tweezers, but smaller pieces have to be shaved off with thinly shaved skin. She also told me that Japanese students who almost never had talked to her were also curious about her shaving and started talking to her. She was actually making parts to fix a broken machine. The machine had been broken for some time, and the professor wanted someone to fix it, so she volunteered.

In the beginning, Fumiko could find a position by demonstrating her metalwork skills in the lab while she attempted to participate in activities such as cleaning the lab and persistently asked other members about the labspecific implicit rules of experiments, such as when one should use tweezers and when one should wear disposable gloves to keep the experimental conditions clean.
In this context, she was doing metalwork in order to fix the lab's broken machine. This was an instance of brokering of a type of technology from another lab. She was also trying to organize her learning environment by forming her informal network through participating in various non-academic lab activities and creating more opportunities for interaction.

She was also brokering her English skills. When I interviewed Japanese students, she was respected, among other things, for her metalwork skills and her competence in English. Students knew that she was in the lab for many hours every day, on weekends, or even on New Year's Eve. (In Japan New Year's Eve is equivalent to Christmas Eve. Students indicated to me that staying in the lab for a long time was a respected practice.)

Fumiko told me that she had never been abroad, but her English was not broken, and she could talk to all members regardless of whether they were from Japan or from abroad. Fumiko said that she felt her English was not so good, but she did not feel shy to speak. However, she felt that the Japanese students in this lab were shy and had mixed feelings toward English. She told me that in her previous lab, everyone used English. There were visiting scholars, and students from abroad and Japanese students were not ashamed to speak broken English.

Bringing skills and different identities as a person with metalwork skills and English skills from her previous lab, she was acting as a broker. She also presented a different way of being by being confident in speaking English though she had never studied abroad.

\section{The case of Jun}

Another Japanese doctoral student, Jun, became a member of this lab when he was a senior undergraduate student, and during his master studies, he went to Europe as an exchange student. After returning from Europe, he presented his study in English in the periodic lab meetings. Max told me that the Japanese 
students began to laugh because they felt it was funny that Jun, who was obviously Japanese, presented to them, the Japanese audience, in a foreign language. However, when the meeting was over, one undergraduate student came up to Max and said in an excited voice that he wants to become like Jun. Max was excited and was smiling with joy when he told me about this. What Jun brought back to this community of practice is the identity of a researcher in the international academic community who did not feel embarrassed to present in English even to his peers.

In an interview, Jun told me that when he went to Europe, he saw how his professor was good at taking a vacation with his family and that his professor left his office early in the evening. He learned how to manage time and how to be efficient. Back in Japan, faculty members stay in their labs for extensive hours and even come to the lab on weekends. In many labs in a variety of fields, it is almost expected that people spend long hours in their labs. Many IGSs, especially the ones from Western countries, find this Japanese habit of staying for a long time in the lab very difficult to accept. Jun saw a model of his future self. He saw how he wanted to be as a scholar, to have his own privacy without sacrificing the quality of his research. Upon his return to the lab, he started being efficient about time.

Students indicated openly or implicitly in interviews that they feel jealous or indifferent about European students taking long breaks, or going home early. Students said, "They (IGSs) are different from us." However, in Jun's case, taking time out or going home early was respected because he was one of them. He not only displayed English speaking skills but also showed a different work and life style to this lab, which he brought back from his experiences in Europe. Thus, it was very meaningful to the lab members that Jun, a Japanese student in the lab, provided a new vision of enjoying one's private life while still being efficient and maintaining the quality of research. Jun brokered new ideas and showed a possible and different identity or mode of being.

\section{The case of Karl}

Karl also discovered and developed different aspects of his self and found his position. His form of participation was virtually non-participation. Before he came to Japan, he thought that he could become a member of the lab without much trouble. In fact, he was a little worried that the Japanese lab might be more advanced than his lab. He was even a little excited to study Japanese and told me that he was a good language learner. He also expected Japanese university students to be more fluent in English. After his arrival in Japan, his Japanese study suffered from a number of unexpected factors, and eventually he gave it up. The Japanese students in the lab were not willing to speak to him in English. He lost interest in interacting with the Japanese students and did not participate in various activities besides academic ones. Karl's fluent English could have become a capital. However, unlike Max, he never came close to the Japanese students. His knowledge, thus, never became a linguistic capital in this community of practice, and he could not broker his capital.

The comparison between Max and Karl shows that discovering and nurturing unique aspects of one's self may lead to participation or to non-participation. For example, if there had been many members like Fumiko or Jun, Karl's participation would have had a much bigger chance. Karl had a potential to be a broker, but the conditions in this particular lab were not favorable to the development of this position.

However, in reality, Japanese students put peer pressure on each other in order that individuals should not speak English. This made Max's position as an interpreter, the person who can speak both English and Japanese, possible. The fact is that Karl's non-participa- 
tion depended on his trajectory of participation - which contrasts with Max's case - as well as on the nature of this community of practice. Karl could not participate in this community of practice because this community of practice did not recognize his capital and could not accept his heterogeneity.

As we have seen, the community of practice and the newcomer mutually construct the mode of participation and the formation of identity.

\section{Positions, capitals and identities}

The above cases show that many varieties of intellectual capital were constructed or became visible. Members' positions and the identities formed in relation to those positions varied too.

Moreover, these cases show what "intellectual or technological capital" is. It became obvious that "intellectual or technological capital" is not given. For instance, being competent in English does not necessarily become a capital in the lab community of practice. Karl's English was very good but never recognized as capital in this lab. On the other hand, Max's English was not so good at first but by participating in the community of practice he came to be "Max the English expert" in the lab. Japanese students wanted to ask for Max's opinion when they had academic or non-academic troubles in English. Max was not a fluent English speaker at first, but he became one by participating in the community of practice and by being accepted as a person with English expertise.

Fumiko had metalwork skills, which she learned at another lab as a master student. These skills were nothing special and no capital in her previous lab, but in this lab they were novel technology and accepted as technological capital. Her English skills were nothing special in her previous lab, but in this lab they were recognized as linguistic capital.

These cases illustrate that knowledge and technology do not become a capital by them- selves. As shown in Karl's and Max's cases, whether one's knowledge or technology become a capital or not, depends upon one's mode of participation in the community of practice as well as upon that one's knowledge and technology are perceived as capital in the eyes of community members.

For instance, as discussed earlier, Max made his English and math skills visible to the Japanese members and to himself through participating in various activities. On the other hand, Karl's English skills were not recognized as capital for Karl himself and for the other members because Karl did not participate in various activities.

Becoming a broker in a community of practice, or participating in a community of practice as a broker, and the transformation of knowledge or skills into capital are mutually constituted activities. Position and identity formation in a community of practice cannot be separated from capital formation. Being recognized by the members of a community of practice as possessing a certain capital can only be accomplished by the simultaneous formation of an identity valued by a community of practice through participation. Thus, capital in a community of practice, or the position or identity that come along with it, are formed through a trajectory of participation across multiple communities.

The cases we have seen so far show that the formation of identity goes beyond Wenger's (1998) interpretation of an individual adjustment of relationships in several communities. For example, a member not only acquires a position as a broker or forms such an identity by bringing in knowledge and technology existing in other places. It is also possible for her or him to bring about a change in the community of practice, and sometimes even change the relationship between communities of practice (such as making a linkage between them or producing a boundary between them). 


\section{Organization of boundaries and identity formation}

The cases thus far illustrate the formation of identity by linking participation in multiple communities. By contrast, in the following examples I shall illustrate identity formation by the organization of boundaries between communities.

The following cases are examples of identities formed by creating boundaries between communities. Wieder's (1974) work gives a relevant example of this kind of identity formation. Wieder describes how a code was formulated at "the halfway house," a rehabilitation center for narcotic-addict felons on parole.

\begin{abstract}
When talking with residents, staff and I often had a relatively friendly line of conversation terminated by a resident's saying, 'You know I won't snitch.' Hearing such an utterance functioned to re-crystallize the immediate interaction as the present center of one's experiential world. 'You know I won't snitch', multi-functioned the immediate environment, its surrounding social structures, and the connections between this interaction and the surrounding social structures. ... Thus saying, 'You know I won't snitch', operated as a re-enunciation, or a reminder of the role relationships involved and the appropriate relations between members of those categories. It placed the ongoing occasion in the context of what both parties knew about their overriding trans-situational relationship.... Besides reminding the participants of trans-situational role relationships they were originally and continuously formulated through such utterances as, 'You know I won't snitch.' (pp. 153-154)
\end{abstract}

In Wieder's case, "You know I won't snitch" made a boundary between residents and staff visible while simultaneously reorganizing the boundary. A community is not something out there but something organized and reorganized continuously by members' words or actions. Furthermore, the resident affirmed his identity by announcing the community to which he belonged. In other words, becoming a member of a community is, at the same time, organizing a boundary and making communities visible.

Willis (1997) and Eckert (1989) reported cases similar to Wieder's. Willis described local and informal communities such as "lads" and "ear holes" organized in schools as institutionalized and formal systems. The lads talking about schoolteachers and ear holes illustrate their view about them. At the same time, this is a part of their conduct of organizing a boundary between themselves and the other side, such as schoolteachers and ear holes. In the following, let us look at a case in the lab.

After Karl joined the science lab and came closer to Max, Max started to reconstruct his European identity. In the beginning of his master student days, he tried hard to become a member in the master student community of practice and participated in many different activities. However, a while after Karl joined the lab he started eating more with Karl and finally stopped eating with the Japanese master students. He often went drinking with Karl, and they discussed their work and shared complaints. As mentioned in the previous section, Karl felt resentment toward Toshi's way of blocking his access to resources and toward the Japanese way of letting this happen.

In this case, Karl and Max were reorganizing their "European" identity as well as the boundary by sharing complaints about the Japanese. In saying that the Japanese had a way of letting this happen, they identified themselves as separate from their Japanese peers, in much the same way as the residents in the halfway house did in Wieder's study.

In the end, Max's process of reconstruction of a European identity was not straightforward. Peter (a student who came to the science lab as a doctoral student a year earlier than Max) commented that, "Max is becoming Japanese, or trying to be one." On the one hand, Max was trying hard to become a part of the community of practice as Peter said but, on the other hand, as I shall illustrate below, he also 
felt bad about the Japanese. Identity formation is a tricky business.

Max told me about his resentment toward the Japanese. "I got tired of being stared at by Japanese people, especially when I am under stress, in a train, or when I am in the gym. When I am exercising, the Japanese are counting how many times I can do (Max was talking about machine exercises), and when I have finished, they will try to do it one time more than I could. As if ' $\mathrm{OK}$, if he (Max) is going to do it that many times, I will do one time more than him.' It made me sick. "' At the beginning Max prepared really hard for classes (classes start in April in Japan), and he was seriously depressed. However, in December, Max surprised me by telling me that he was going home for Christmas. When I asked him, “Aren't you going to miss classes?", he replied, "I don't care", with a smile on his face. When a Japanese student heard this, he was very surprised and wanted to have confirmed whether Max knew that he was going to miss a major lab progress report meeting. The Japanese student was so surprised that he asked Max whether he had told the professor or not. Max replied that he had told the professor but added that the professor was so busy that he probably did not quite understand the implication of what Max was telling him. This episode shows the emergence of Max's new identity, an identity of resistance toward the Japanese and a "European" identity. It was a different European identity than he had before he came to Japan. In fact, he came to Japan because he did not have this identity of resistance toward the Japanese.

1 Now the situation has been changing rapidly. Dying your hair is very common, among young or old, and having light colored hair, or even purple hair, does not stand out so much any more. In addition, having a higher Caucasian population in Japan and seeing them on TV made people more used to seeing them. However, when Max experienced this, the situation was worse for people like him.
The cases above illustrate that participation in a certain community of practice goes beyond just becoming a member in a community of practice. It is associated with finding and nurturing a unique part of oneself. The significance of these cases differs from the cases of brokering. Like in the case of brokering, the instances of the formation of a heterogeneous self, which we saw in this section, may be understood as brought about by a trajectory of participation across communities. Furthermore, as we have seen above, these cases of identity formation cannot be reduced to the individual action of adjusting the relationship between communities for an individual. Rather, like the narcotic-addicts who organize a certain community or make the community visible by telling the code, the members form unique selves by forming subgroups in reality.

\section{Conclusion}

In this paper, I first illustrated that communities of practice are composed of various interwoven activities and occasions, such as formal/informal and front stage/backstage. Accordingly, a trajectory of participation in a community of practice cannot be described as a linear process, such as from peripheral to full participation, but as participation in multi-layered activities and occasions, which mutually constitute each other.

Second, I described the mode of participation as finding or constituting one's unique position rather than viewing participation as becoming an undifferentiated member. The cases of IGSs and Japanese students illustrate that the formation of identity in a community of practice may be conceptualized as discovering and constituting unique aspects of one's self through participating in practice rather than merely becoming a member of a community of practice. In short, the mode of participation in a community of practice is not a linear process. It is multiple rather than linear. 
If modes of participation are multiple, they may be conducive to finding or constructing one's unique position rather than being a linear process. By finding a position in a community of practice, it is possible to discover and form a different self. The actual structure of participation may then be redefined as finding a new position involving the creation of a new identity, which goes beyond merely becoming a member of a community of practice. In short, the formation of identity in a community of practice may be conceptualized as discovering and constituting unique aspects of one's self.

The constitution of one's unique position and the creation of a new identity in a community of practice are closely related to the realization of intellectual and technological capital. Because of their particular intellectual and technological capital, participants are able to obtain their unique position and create a new identity. However, intellectual and technological capital is not just out there. Rather, a person's capital becomes visible or constituted through his or her participation across multiple communities.

\section{References}

Bourdieu, P. (1977). "The economics of linguistic exchanges.” Social Science Information 16(6), 645-668.

Brown, J. S. \& Duguid, P. (1991). “Organizational Learning and Communities-of- Practice: Toward a Unified View of Working, Learning, and Innovation." Organization Science. 2(1), 40-57.

de Beauvoir, S. (1953). The second sex. trans. H. M. Parshley (In E. Goffman, 1959. The Presentation of Self in Everyday Life.). New York: Knopf.

Dreier, O. (1999). "Personal trajectories of participation across contexts of social practice.' Outlines, 1, 5-32.
Eckert, P. (1989). Jocks and Burnouts: Social categories and identity in the high school. New York: Teachers College, Columbia University.

Goffman, E. (1959). The presentation of self in everyday life. New York: Doubleday \& Company Inc.

Lave, J. and Wenger, E. (1991). Situated Learning: Legitimate peripheral participation. Cambridge: Cambridge University Press.

Lave, J. (1997). "On Learning." Forum Kritische Psychologie 38, 120-135.

Ueno, N. (1999). Shigoto no nakadeno Gakushu: Jyoukyouronnteki approach (Learning in Workplaces: Situated approach.). Tokyo: University of Tokyo Press.

Wenger, E. (1990). Toward a theory of cultural transparency. Elements of a social discourse of the visible and the invisible. Doctorial Dissertation. University of California, Irvine.

Wenger, E. (1998). Communities of practice. Cambridge: Cambridge University Press.

Wieder, D. L. (1974). "Telling the Code." In Turner, R. (Ed.) Ethnomethodology. Penguin, 1974, pp.144-172, originally published by Mouton de Gruyter, as Language and Social Reality, 1974.

Willis, P. E. (1977). Learning to labour: How working class kids get working class jobs. New York: Columbia University Press.

Østerlund, C. S. (1996). "Learning across Contexts: A field study of salepeople's learning at work." Monograph Series, Vol. 21, 1, Department of Psychology, University of Aarhus. 